\title{
The Design of a One-Stop Tourism Portal in Langkawi Island using Location Searching Method
}

\author{
Wong Poh Lee ${ }^{1, a}$ Mohd Azam Osman ${ }^{1, b}$ Tarmiji Masron ${ }^{2, c}$ \\ ${ }^{1}$ Sch. of Computer Sciences, Universiti Sains Malaysia, 11800 USM, Penang, Malaysia \\ ${ }^{2}$ Sch. of Humanities, Universiti Sains Malaysia, 11800 USM, Penang, Malaysia \\ awongpohlee@gmail.com, bazam@cs.usm.my, ${ }^{\mathrm{c}}$ mmiji@usm.my
}

\begin{abstract}
The study on online tourism portals and geographical maps has become a common research endeavor. Maps consisting of countries are digitally available to enable location-based searching, getting directions and information of places. Human beings are depending on the widespread of technologies such as Global Positioning System(GPS) to search places and to get directions due to the vast development and changes at certain areas. Many places use similar names that cause confusion when searching for a specific location. Sometimes, there are too many results returned including irrelevant results. In this paper, we discuss a simple method to search for tourist locations based on keywords, GPS coordinates and specified parameters. The design and implementation of a one-stop tourism portal will also be explained.
\end{abstract}

Keywords: Tourism Portal, Location Searching, Web Portal

\section{Introduction}

Many studies have been conducted related to tourism in boosting a country's economy.[1,2] This includes facilitating users in terms of location searching and the use of GPS to locate specific places in a timely manner. As technologies evolve, people are starting to make full use of the available resources available on the Internet before they venture or travel to a country. The concept of backpacking (travel) is becoming a trend among the communities as it saves money and there are less time constraint compared to participating in a tour.[3] However, though graphical maps are available, they are less populated with information causing searching is difficult and with limited results. Besides, major categories of places are difficult to locate as locations tend to be scattered around in a map. Therefore, the objectives of this paper are as follows:

- To an easier searching method based on several options such as keyword search and nearby search.

- To identify major categories of places in a map

- To boost tourism by providing a one stop data center to facilitate tourist in Langkawi Island.

The study was conducted in Langkawi Island located in Kedah, Malaysia. However, this method can be further extended to other locations.

\section{Background Study}

Studies are conducted on existing systems related to online tourism portals and Geographic Information System (GIS). 
The purpose of these studies is to identify the features and methods used in the existing systems.

\subsection{Online Tourism Portal}

M.T. Banday et al. [4] have identified the requirements and guidelines in developing a web portal for Kashmir Tourism Industry. The authors have come up with a strategy in the development of web portal as shown on Fig. 1 .

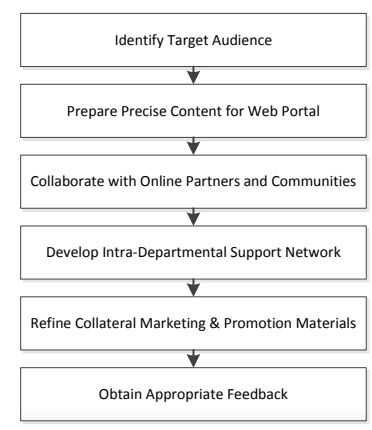

Fig. 1 : Web Portal Strategy [4]

In a paper by $\mathrm{H}$. Mili et al.[5], the authors use an ontology method in developing an online tourism portal.

E.S. Khorasani et al. [6] studied the issues faced by tourist where unrelated information is found in online tourism portals. The authors propose a framework in overcoming this using data mining, web mining and knowledge management techniques.

\subsection{Geographic Information System}

In a GPS which are commonly available in the market, location searching is based on a Two Point Referencing technique. However, Y.R. Wang et al [7] proposes the use of a Three Point Referencing technique to improve the accuracy where the additional point acts as an improvement with reference to the existing two points.

A graph-matching algorithm searching method is proposed by A. Mademlis et al[8]. The authors analyze the images captured from the map and generate a graph. Keywords are matched according to the generated graph.

\section{System Design}

The design of the one-stop tourism portal consists of several sections as mentioned below:

- Database Design: To store information of locations which includes information such as description, address, e-mail, contact number and others.

- Image Gallery: Displays images of the location.

- Search Engine: Performs search functions based on user's preference.

- Interface Design: Displays information in an interactive manner.

- Map Engine: Generates a graphical map in a web interface.

Our study focuses on the Search Engine which functions as a tool to help users locate and retrieve more information of their desired tourist location. Fig. 2 shows the flowchart of the location searching method used in the one-stop tourism portal.

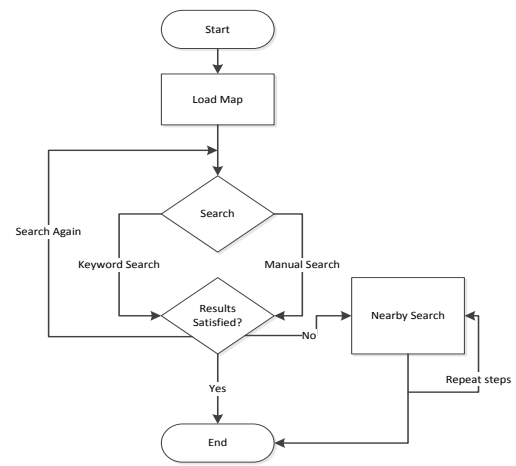

Fig. 2: Flowchart of the Location Searching Method

Firstly, the graphical map is loaded to display an overview of the Langkawi Island map. In order to meet the users search preference, users have two choices for searching the tourist location. They can search manually or hovering the 
mouse cursor over the map. If the results are not satisfied, the portal will keep track of the location category and to perform a nearby search based on the returned results of the first search. Location categories consist of accommodations, entertainment centers, restaurants and others. These steps are repeated until the results are satisfied.

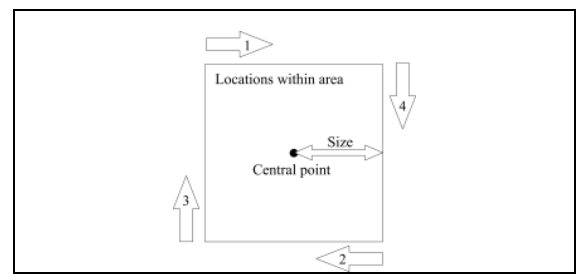

Fig. 3 : Locations Within An Area

Based on Fig. 3, the size of the square measuring from the middle point to the edge is set to 0.01 which is approximately 1.11 kilometers. The size represents the area coverage where larger values have higher chances to obtain more results. The rules to compute the area is as follows:

i. Latitude is less or equals to (Latitude of Central Point + Size)

ii. Latitude is more or equals to (Latitude of Central Point - Size)

iii. Longitude is more or equals to (Longitude of Central Point - Size)

iv. Longitude is less or equals to (Longitude of Central Point + Size)

The reason a square is chosen because it requires less computation compared to a circle which is:

(Latitude - Latitude of Central Point) $)^{2}+$ (Longitude - Longitude of Central Point) ${ }^{2}$ is less than Radius ${ }^{2}$.

Furthermore, a square covers wider area compared to a circle by $78.6 \%$ with the same radius.

\section{Implementation}

We have designed and developed a prototype system of the one-stop tourism portal which provides a search function to search for locations based on user's preferences. The portal is developed using ASP.net and taking advantage of Google Maps library to enable the map to be plotted with assigned coordinates.

Fig. 4 shows the interface of the portal where keywords can be entered to do a search. The users have a choice to continue searching nearby locations and to show images related to the selected location.

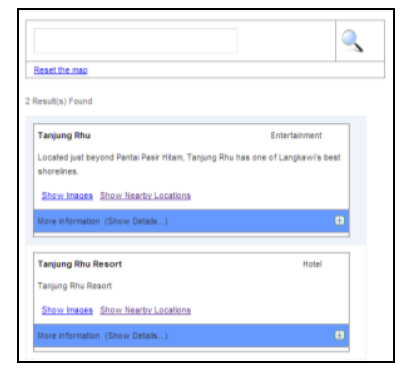

Fig. 4 : Sample Search Results

Fig. 5 shows the locations which are plotted on the map based on the search results shown on Fig. 4. Users have an option to further view the search results in the form of a list or in the graphical map.

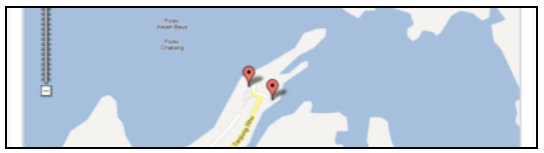

Fig. 5 : Locations Plotted on the Map

\section{Results and Discussion}

We have selected 3 random points in the map to compute a set of total number of nearby results found as shown in Table 1 . We performed 3 layers of nearby searches to the first random location.

Based on Table 1, it is found that the results generated from the search returns low number of search matches. Instead of combining all the search results, the onestop tourism portal is able to filter out certain locations where it starts to focus 
nearer to the user's search location. When the users have found the desired location, more information such as address, e-mail and contact number can be retrieved. An additional feature provided by the portal includes directions to the desired location.

Table 1: Results Gathered from the Searching Based on 3 Random Locations

\begin{tabular}{|l|c|c|c|}
\hline \multirow{2}{*}{$\begin{array}{l}\text { Random } \\
\text { Locatio }\end{array}$} & \multicolumn{3}{|c|}{ Total Number of Nearby Results Found } \\
\cline { 2 - 4 } & $\begin{array}{l}\text { First } \\
\text { location } \\
\text { selectio } \\
\mathrm{n}\end{array}$ & $\begin{array}{l}\text { Random Sub- } \\
\text { location of } \\
\text { First Nearby } \\
\text { Search }\end{array}$ & $\begin{array}{l}\text { Random Sub- } \\
\text { location of } \\
\text { Second Nearby } \\
\text { Search }\end{array}$ \\
\hline $\begin{array}{l}\text { Random } \\
\text { Locatio } \\
\text { n One }\end{array}$ & 3 & 4 & 2 \\
\hline $\begin{array}{l}\text { Random } \\
\text { Locatio } \\
\text { n Two }\end{array}$ & 2 & 0 & 0 \\
\hline $\begin{array}{l}\text { Random } \\
\text { Locatio } \\
\text { n Three }\end{array}$ & 2 & 1 & 3 \\
\hline
\end{tabular}

${ }^{1}$ Latitude: 6.455358, Longitude: 99.825817

${ }^{2}$ Latitude: 6.370214, Longitude: 99.67155

${ }^{3}$ Latitude: 6.43088, Longitude: 99.726849

However, based on several random searches conducted by randomly chosen participants, several feedbacks and suggestions are collected and summarized as follows:

- Certain locations are not available in the map.

- More types of categories should be included.

- Support mobile devices to ease tourist during their visit.

\section{Conclusion}

We found out that more studies need to be conducted on the search engine to further improve the location searching method. More parameters such as location characteristics, popularity and others should be added into consideration. The one-stop tourism portal needs to be populated with up-to-date information regularly in order to generate better and more accurate search results.

\section{References}

[1] K. Chulwon, "E-Tourism: An Innovative Approach for the Small and Medium-Sized Tourism Enterprises (SMTES) In Korea", Organisation for Economic Co-operation and Development, OECD iLibrary, 2004.

[2] L. Sebastia, I. Garcia, E. Onaindia, C. Guzman,"e-Tourism: A Tourist Recommendation and Planning Application", 20th IEEE International Conference on Tools with Artificial Intelligence (ICTAI '08), pp.89-96, 2008.

[3] Backpacker Tourism, Retrieved November 25, 2012 from http://archive.tourism.nsw.gov.au/Bac kpacker_Tourism_p726.aspx

[4] M.T. Banday, S. Afzal, "Web Portal for Kashmir Tourism Industry: Design Guidelines", Sprouts: Working Papers on Information Systems, 2008.

[5] H. Mili, P. Valtchev, Y. Charif, L. Szathmary, N. Daghrir, M. Béland, A. Boubaker, L. Martin, F. Bédard, S. Caid-Essebsi, A. Leshob, "E-Tourism Portal: A Case Study in OntologyDriven Development", SpringerVerlag Berlin Heidelber, Springer, , pp. 76-99, 2011.

[6] E.S. Khorasani, S. M. Naghibizadeh, "A Framework to Improve E-Tourism Experience by Using Intelligent Portal,", Seventh International Conference on Information Technology, Las Vegas, Nevada, USA, ISBN: 978-07695-3984-3, pp.1226, 2010.

[7] Y.R. Wang, C.Y. Tsai, Y.C. Chang, H.C. Yang, M.C. Chen , "Ubiquitous Navigation Based on Physical Maps and GPS," International Symposium on Computer, Consumer and Control (IS3C),pp.101-105, 2012.

[8] A. Mademlis, M.G. Strintzis, K. Kostopoulos, K. Moustakas, D. Tzovaras , "A Map-Search FrameWork Based on Attributed Graph Matching," MultiMedia, IEEE , vol.17, no.3, pp.24-33, 2010. 